to ensure the most efficient use of highly trained professional men and women - a problem that becomes the more important as their salaries are raised. A good case is well presented, which would be strengthened by evidence of more flexibility and more vision and of recognition that teaching is, above all, a vocation.

\section{The Teaching of Biology}

IN his inaugural lecture at the University of Leicester, Prof. H. C. Kornberg, professor of biochemistry, first discussed the unity of life and then went on to examine the implications in the present provisions for biological oducation (The Unity of Life. Pp. 21. Leicester: The University Press, 1962. 3s.). The subdivision of living organisms into bacteria, plants and animals rests on the differences which are emphasized in their academic study. In consequence, universities in general tend to train specialists in one or two of these branches of the life sciences and, in order to gain admittance to the universities for their pupils, schools adopt the same procedure. There is from the outset a fragmentation of biology, which will become more severe as new biological specialties arise. The multiplication of specialties will face the would-be student of biology with an increasingly bewildering multiplicity of degree courses, all of which will inevitably tend, more and more, to overlap one with another. If this trend continues, it is not inconceivable that students might ultimately graduate with a detailed knowledge of biophysics, biochemistry and molecular biology but with only a hazy knowledge of what plants and animals look like. This multiplication of specialties, with the concomitent tendency to create a corresponding multiplicity of specialist departments, will also impose an increasingly severe strain on the universities themselves, with the result that the smaller universities, at least, may soon find themselves unable to provide the staff, space and equipment necessary to accommodate this mushroom growth. These dire tendencies can be reversed if, in the future development of biology, the present divisions based on the differences between living organisms are complemented by academic units based on the fundamental similarity of life processes. This might find its physical expression in the creation of schools of biological science which might house, under one roof, the specialties which operate at the cellular and functional level at which a unitary approach has already been achieved.

\section{Standardization of Reporting Dental Diseases and Conditions}

IT has been realized for a long time that in any medical examinations carried out for comparative purposes the most careful standardization is necessary, and this involves control of such factors as the method of examination and the exact definition of diagnostic criteria. This is a particular problem in the field of dental epidemiology, because of the difficulty in defining the threshold levels at which it is considered that undoubted dental or gingival pathology is present. A recent report issued by the World Health Organization is concerned with establishing definitions and criteria for measuring the prevalence of dental caries, gingivitis, periodontal disease, dento-facial anomalies, tooth eruption, and prosthetic requirements (Technieal Report Series No. 242. Standardization of Reporting Dental Diseases and Conditions. Report of an Expert Committee on Dental Health. World Health Organization, Geneva,
1962). The criteria are simple and well defined; and it is emphasized that the methods recommended are mainly for large-scale studies of differences between populations. If finer comparisons have to be drawn the Committee considers that refinements can be added to the basic data according to the requirements of the particular investigation. There is also a brief section on the planning, reporting and writing of results and examples of dental survey forms. The report fulfils its stated purpose very well and represents a useful contribution to the advancement of dental epidemiology.

\section{Natural History Museum in Alma-Ata}

I. G. Galuso, V. S. Bazhanov and T. N. Nurumov (Priroda, 3, 62; 1962) provide a brief description of a new Natural History Museum in Alma-Ata, the capital of Kazakhstan. It contains more than 2,500 exhibits in the fields of geology, botany and zoology, and its aim is to represent all the varied nature of Kazakhstan. The Museum was built and organized by the Kazakh section of the U.S.S.R. Academy of Sciences.

\section{The British Museum (Natural History): Recent Acquisitions}

Among the more important and interesting items recently acquired by the British Museum (Natural History) is a collection of young stages of British grasshoppers (Acrididae), presented by Prof. O. W. Richards and Miss N. Waloff. It is unique, comprising about 1,000 specimens in spirit, including every nymphal instar of all ten British species. The Department of Entomology has also been presented with 242 slides of Streblidae, the major part of the unique collection of Mr. Boris Jobling, of the Wellcome Foundation.

\section{The Bernice P. Bishop Museum}

UNDER the attractive title of Science and Education and with an arresting format, the activities for 1961 of the Bernice P. Bishop Museum in Honolulu are described in a far from formal manner (Pp. 29. Honolulu, Hawaii: Bernice P. Bishop Museum, 1962). The chief event was the completion of Kilolani-the Hawaii Planetarium and observatory. This was the climax of eight years of planned improvement of educational facilities of the Museum. Kilolani consists of three separate but connected units. The first is an appropriate entrance exhibit gallery, then the Planetarium proper, seating about 100 visitors and equipped with a Spitz instrument. The third unit is an observatory containing a $12 \cdot 5$-in. reflecting telescope, but capable of accommodating a larger instrument if this proves desirable in the future.

\section{U.S. Federal Aid in Wildlife Restoration}

The Federal Aid in Wildlife Restoration Act was approved in September, 1937, and popularly known as the Pittman-Robertson Act. It was designed to help check the depletion of the wildlife in the United States and stimulate its restoration. Since wildlife is a product of the land, its restoration depends on providing suitable living conditions for the desirable species. The developmental work that favours the increase of wild birds and mammals contributes also to the conservation of soil and moisture, which are essential to the maintenance of a prosperous agriculture. The income from the sale of hunting and fishing licences is practically the only revenue available to finance the activities of State fish and game 